\title{
Micromundo@Salamanca (SWI): búsqueda de nuevos microorganismos productores de antibióticos mediante una estrategia de ApS
}

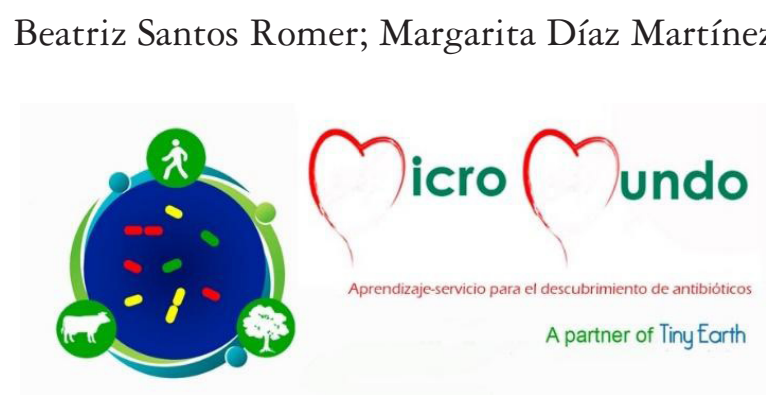

B

STE PROYECTO PERSIGUE dos objetivos principales: dar a conocer el problema de la resistencia a los antibióticos y la generación de nuevas vocaciones científicas entre los jóvenes.

Además, otro de los objetivos es:

- Compaginar el aprendizaje de los alumnos universitarios con su contribución activa en resolver un problema actual y acuciante de la salud como es la resistencia a antibióticos.

Este proyecto permite a los alumnos del Grado en Biología aprender y concienciar sobre uno de los problemas más importantes de la salud mundial: la resistencia a antibióticos; a la vez que lo difunden a alumnos de Secundaria y Bachillerato realizando un proyecto real de investigación.

Los objetivos específicos planteados son:

a) Consolidar los conocimientos relacionados con esta problemática.

b) Compartir esos conocimientos con alumnos no universitarios, sus familias y la sociedad en general, fomentando, además, las habilidades docentes futuras de nuestros graduados.

Los agentes implicados en el proyecto son:

- Equipo de trabajo formado por profesores e investigadores (SWI-IPs). 
- Alumnos voluntarios de Grado de la Facultad de Biología (SWI-TAs).

- Alumnos de los centros de secundaria y sus profesores (SWIs).

Para el desarrollo de las actividades hay varias fases:

1. Reclutamiento de alumnos de Grado.

2. Selección de los centros de secundaria que vayan a participar.

3. Realización de una formación inicial de los alumnos de Grado.

4. Realización del proyecto real con los centros de secundaria seleccionados dirigido por los alumnos de Grado.

5. Actividades de divulgación a la sociedad mediante

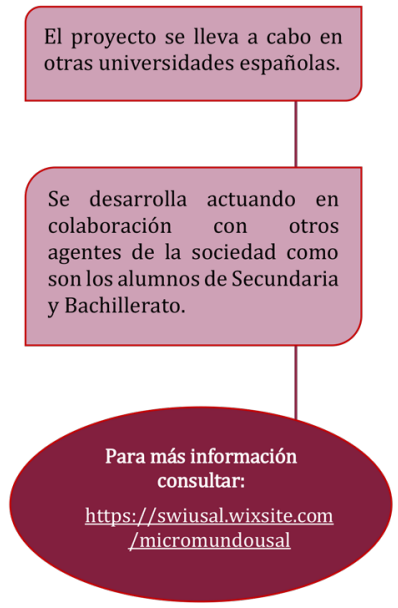
la organización de una jornada de clausura con invitación a investigadores en el campo de la resistencia a los antibióticos.

Se trata de un proyecto muy motivador para los estudiantes de Grado y ha permitido consolidar sus conocimientos relacionados con el problema al que nos referimos. Además, hay que destacar la alta implicación de los alumnos en el desarrollo de la actividad.

Para tener un indicador que avale lo mencionado, se realizó un cuestionario anónimo y voluntario de satisfacción de los SWI-Tas al final del proyecto.

Este proyecto se encuentra en la metodología ApS. Concretamente la repercusión del mismo en la sociedad se encuentra en la implicación de los alumnos no universitarios, sus familias, etc.

Además, profundiza en dos aspectos de la carrera profesional de los futuros graduados: docencia e investigación.

En cuanto a la divulgación: se ha realizado una jornada de clausura abierta al público donde se presentan los resultados del proyecto. 